\title{
Re-Engineering Technical Education in Industry Through Interactive Multimedia Computer-Based Training
}

\author{
Yolanda Kennedy and Erika Rogers
}

\begin{abstract}
This paper describes current work on reengineering a short technical course in the area of NonDestructive Evaluation/Inspection (NDE/I) sponsored by Boeing's Defense and Space Group. The subject of the course is Eddy Current Testing, and is currently taught over a period of two days using traditional view foils and hand-built artifacts. An overview of some of the course material is presented together with how techniques such as task analysis and storyboarding are being used to design interactive multimedia training modules to support this course.
\end{abstract}

\section{Introduction}

An important aspect of engineering education is in the specialized on-the-job technical training provided by many industrial employers. These courses are often short, material-intensive, and of immediate relevance to the employee's job performance or certification, and many industries are now seeking more effective ways to improve their educational programs without having to hire more experts. Computer-based training (CBT) methods have been used for a number of years as effective solutions to this problem. The increased affordability of powerful desktop systems with multimedia capabilities has created opportunities to extend these methods to include more extensive interactivity using graphics, imaging, sound and video technologies. Advantages of such systems include better material retention, reduced training time, and improved delivery cost-effectiveness over more traditional training methods [3].

Before investing in such technologies, companies must consider the effort needed to re-engineer the course materials into a form that not only provides the required course content, but which, ideally, takes advantage of the technological capabilities not available in traditional methods. Interactive Multimedia Computer-Based Training (IMCBT) typically has a high cost of development since it requires not only organization and design of the course content, but an aesthetically pleasing presentation (visually and aurally), as well as technical skills to implement these concepts in a multimedia authoring environment. A successful IMCBT team might include a subject matter expert, an instructional designer, a programmer, an artist and a narrator. Offsetting the high cost of development are the cost savings realized in the delivery of the training materials. Increased accessibility in the form of longer available practice hours, "just in time training" where lessons can be repeated or reviewed just before performing particular tasks, as well as portable instructions for technicians at remote sites performing unplanned inspections, all contribute to substantial cost effectiveness once the IMCBT programs are in place .

Sometimes the cost of development can be somewhat reduced by re-engineering the traditional materials already in place in the training program. The advantage of this is that often much of the course content and some of the course organization and goals are already defined. However, a disadvantage is that there may be a tendency to just re-work the original flow of information, without taking full advantage of the non-sequential nature of the multimedia paradigm. The design trade-offs must be evaluated in the context of how the IMCBT system will be used: whether as a support for instructor-led classes, or as stand-alone student-centered training mo dules.

The following sections describe work on a project to help re-engineer a training course in the area of NonDestructive Evaluation/Inspection (NDE/I) sponsored by Boeing's Defense and Space Group. An overview is presented of some of the techniques used to design parts of 
the IMCBT modules, including task analysis and storyboarding.

\section{Application to Industry}

The Boeing Company is one of the leading companies in developing CBT courses, and is well known for its training expertise in industry. Although CBT has been used extensively at Boeing for maintenance and flight training, it has not previously been employed in the aircraft nondestructive evaluation inspection arena, although CBT is particularly suited to this subject matter: it contributes to the reduction in the cost of laboratory equipment, and the cost of instructors for training employees. Methods and applications that are occasionally used for inspections can easily be incorporated into simulations. The expense to retain a trained staff in aircraft maintenance can be high because a number of these inspections occur infrequently. This problem can be solved by using CBT for certain specialized inspections as a review for technicians.

The Non-Destructive Evaluation/Inspection program includes three major courses: Eddy Current Testing, Ultrasonic Testing, and Penetrate Testing. Of these, Eddy Current testing is used in approximately $80 \%$ of the inspections, and was therefore chosen as a candidate for re-engineering. This course is currently taught in a classroom environment with a range of students from vocational to engineers. It is divided into theory and application sections, and is taught periodically for two eight-hour days at a time. The theoretical subject matter is presented by an instructor using view foils and hand-built artifacts, while the practical part of the course includes hands-on training inspections with specific equipment such as meters, probes and a range of metal standards. There is no examination required to pass the course -- technicians are tested by certification procedures throughout intervals of their careers. Many of the concepts involve understanding electro-magnetic properties at an atomic level, and are difficult to visualize on paper. The IMCBT modules for this course are expected to help students understand the underlying theory as well as to interact with the eddy current instrumentation and see effects of instrument setting changes on inspection signals.

\section{Design Techniques}

The re-engineering of a traditionally-presented training course into an interactive multimedia program poses numerous challenges. First of all, the general content and goals of the course must be clearly defined, and a particular subject identified which is appropriate for development. Once the general topics are known, a more detailed description must be designed, which not only incorporates the logical flow of information, but which allows the interactivity typical of computer-base training systems. Finally, within each different lesson, the "active" portions must be identified to take advantage of the multimedia capabilities of the system. When should something move? How realistic should the motion be? Where can interactivity be combined with motion to simulate a real world situation? How can "facts" be balanced with demonstrations? This is an iterative process, and no single course design technique seems to be adequate for handling the different aspects needed. The following subsections describe some techniques used for design of computer-based training techniques with specific examples from our work on the fastener-hole inspection portion of the non-destructive inspection program.

\section{Course Mapping}

Course mapping is a technique used to structure the components of a training program in a logical manner. It emphasizes a design process where the learner has the prerequisite knowledge or skills necessary to begin a new learning experience, and this is accomplished by designing a "map" that ensures that the parts of the program as well as the total program consistently move the learner to a desired performance level [1]. The overall pieces of the training program are related to each other in a hierarchical fashion, where the goals of each level are established, and then the relevant prerequisites are determined. Fig. 1 shows an example of a top level view of a course map for the NDE/I program, which corresponds to the organizational structure currently used in presenting the course. 


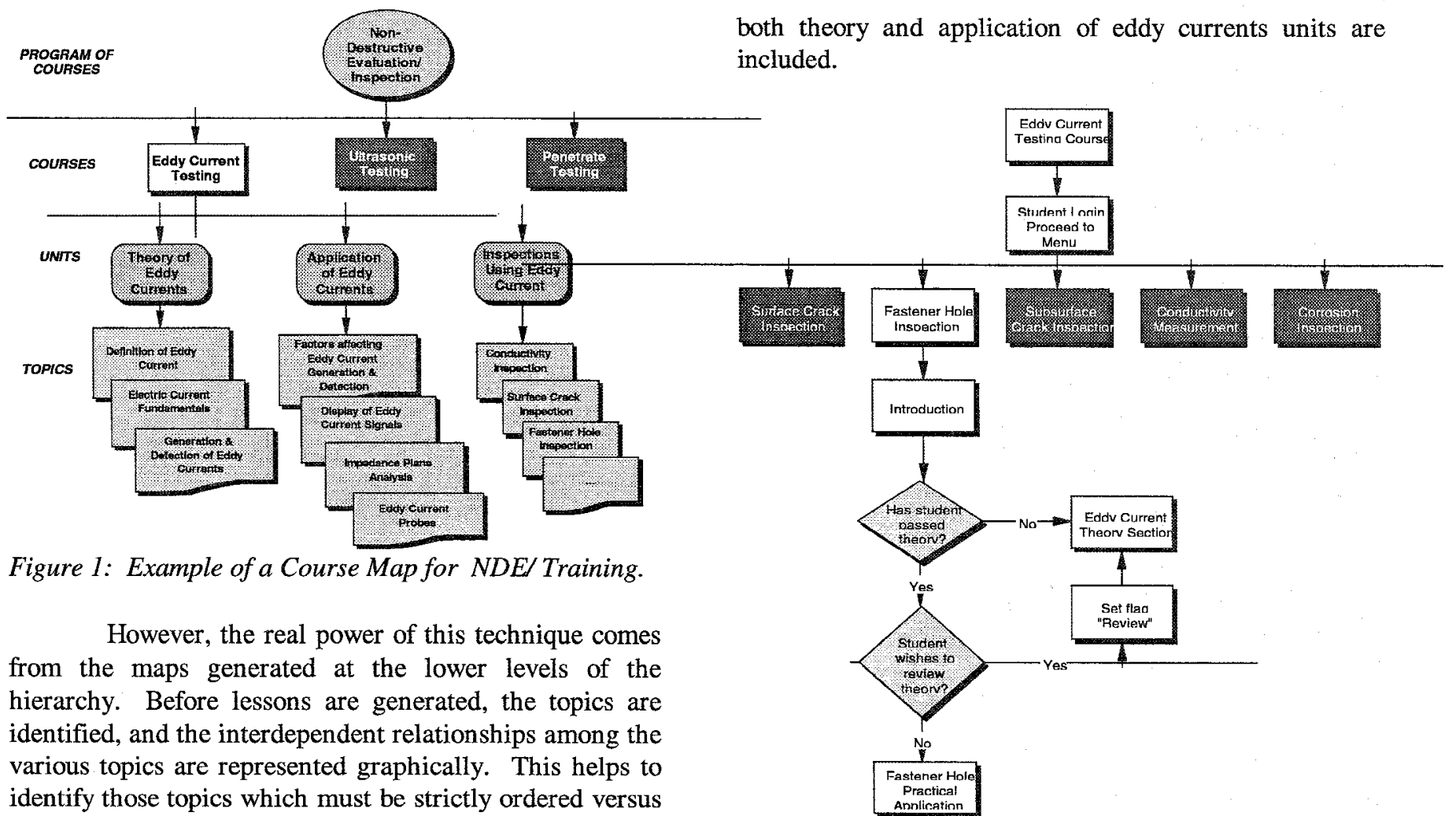
those which provide some degrees of freedom in order of presentation. This can be particularly useful for computer-based training, where the flow of presentation may differ according to the different students' needs. (In the traditional classroom setting, the instructor commits to a particular sequence of presentation, which all the students see and hear at the same time.) At the next level in the course map, the units are designed to represent the relationships between learning outcomes. These outcomes establish what skills and knowledge the learners are expected to have at each stage. Since the full course mapping technique was not utilized in the first prototype of the fastener hole inspection module, the topics and units shown in Fig. 1 represent a strictly sequential presentation of information from left to right. The weakness of this is that interdependencies across topics are not explicitly represented, thus limiting the range of navigation which could be exploited by the interactive multimedia capabilities.

\section{Flowcharting}

The flow of control for the high-level interaction that was developed for this module is shown in Fig. 2. A standard flowcharting technique was used with a menu selection paradigm. Fig. 3 shows a partial sequence of topics to be presented for the Eddy Current Theory Section, and it is interesting to note that the topics from 


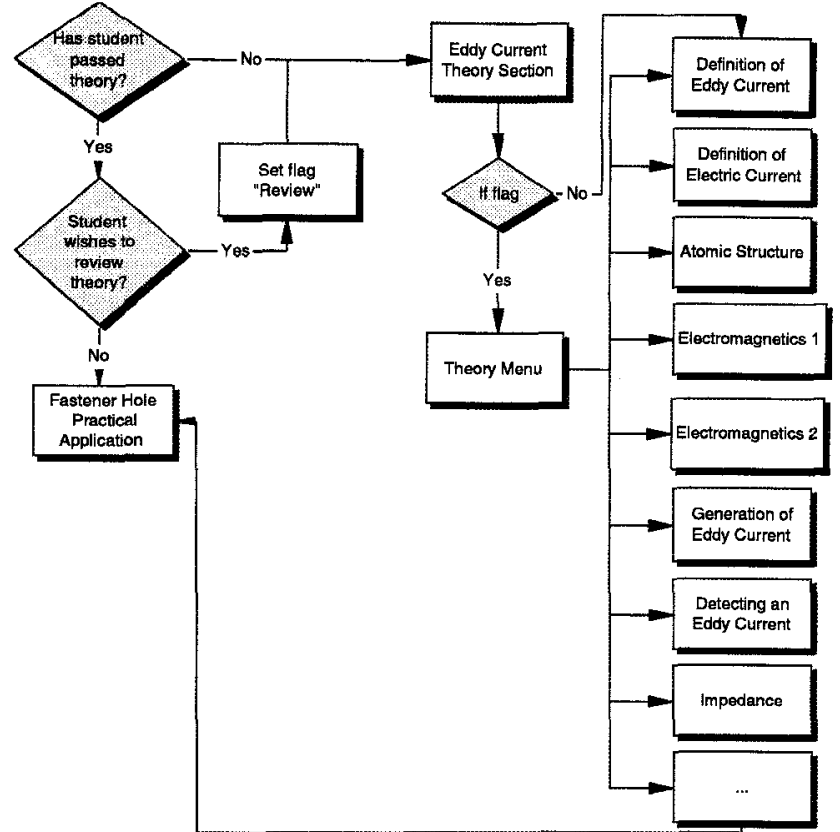

Figure 3: Flowchart of Eddy Current Theory Section.

\begin{tabular}{|c|c|c|c|c|}
\hline Time & $\begin{array}{l}\text { Topic/ } \\
\text { Task }\end{array}$ & $\begin{array}{c}\text { Task Analysis/ } \\
\text { Objectives }\end{array}$ & CBT Activity & $\begin{array}{c}\text { Re- } \\
\text { sources }\end{array}$ \\
\hline & $\begin{array}{l}\text { Definitio } \\
\mathrm{n} \text { of an } \\
\text { eddy } \\
\text { current }\end{array}$ & $\begin{array}{l}\text { Student will be able } \\
\text { to define an eddy } \\
\text { current. } \\
\text { Student will } \\
\text { recognize that they } \\
\text { need to understand } \\
\text { the existence and } \\
\text { characteristics of } \\
\text { electric currents and } \\
\text { magnetic fields in } \\
\text { order to understand } \\
\text { eddy current } \\
\text { inspection. } \\
\text { "An eddy current is } \\
\text { an induced electric } \\
\text { current flowing in a } \\
\text { conductor." }\end{array}$ & $\begin{array}{l}\text { Move from the } \\
\text { image of eddy } \\
\text { current coil and } \\
\text { structure to } \\
\text { showing } \\
\text { currents flowing } \\
\text { in the structure } \\
\text { and define eddy } \\
\text { current. } \\
\text { Comment that } \\
\text { the induced } \\
\text { current (eddy } \\
\text { current) } \\
\text { requires a } \\
\text { changing } \\
\text { magnetic field } \\
\text { which will be } \\
\text { explained. }\end{array}$ & $\begin{array}{c}\text { VF } \\
5926\end{array}$ \\
\hline
\end{tabular}

Figure 4: Task Analysis for Eddy Current Theory topic.

\section{Storyboarding}

The final stage of the design process is called storyboarding, and this is where the "look and feel" of the actual multimedia objects are determined, in conjunction with the goals dictated by the task analysis. Ideally, each frame of the interaction should be outlined in sufficient detail with specifications for the graphics, text, sound, video and animation components so that the actual programming becomes a straightforward process. In our project, the instructors decided that the graphics should maintain the general look of the view foils on which they are based, since these diagrams were already available electronically, and this would maintain some consistency with the instructor's classroom presentation. Therefore the storyboard was typically a copy of the view foil itself annotated with notes on the interactivity, simulation and/or motion needed. Figs. 5 and 6 are screen shots of two demonstrations in the early part of the theory section. In the first part, the concentric eddy currents move in a circular pattern, and when the user clicks the switch to close the circuit, the next screen adds the moving magnetic field which is orthogonal to the eddy current. Other demonstrations allow the user to drag a compass around the screen, and to see how the needle changes when it encounters the magnetic field. These simulations combine the actions the student would experience using the hand-built artifacts, together with a display of the invisible electromagnetic properties underlying the behavior of the instruments.

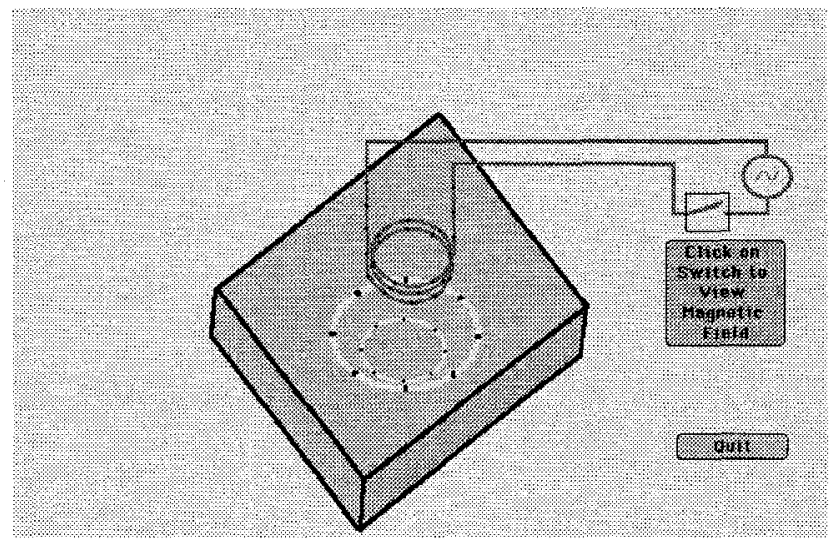

Figure 5:.Animated Eddy Current with Clickable Switch.

\section{Conclusion}

The re-engineering of traditionally presented technical short courses into interactive multimedia modules is a challenging and non-trivial task. Design techniques such as task analysis, storyboarding, and course mapping can be used to organize the subject matter and information flow in 


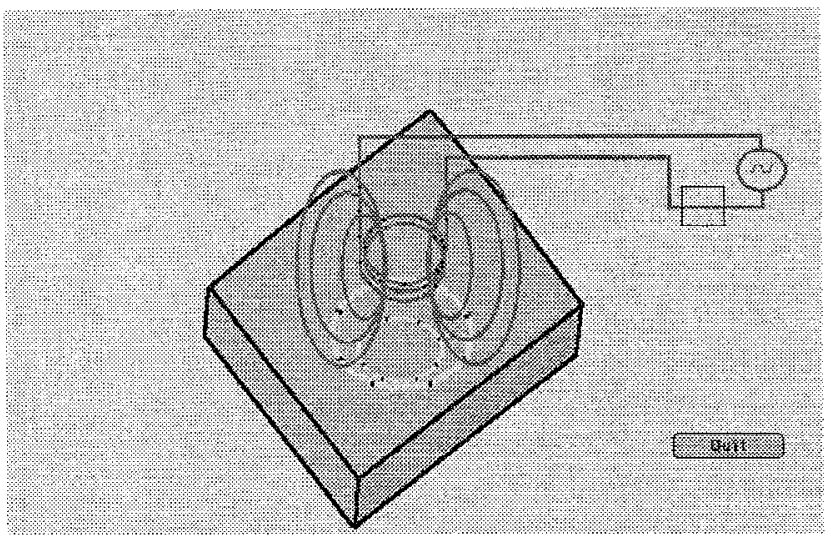

Figure 6: Animated Eddy Current with Magnetic Field.

a more engaging and adaptive manner, but even with these tools, the development process is timeconsuming and labor-intensive. The application of these techniques to the fastener hole inspection portion of the Eddy Current course has led to the development of a prototype module written in Authorware, which will eventually be used to supplement existing training material, and which will be tested and evaluated by instructors, students, and training perso nnel at Boeing.

\section{Acknowledgments}

The work described in this paper is supported by Technology Reinvestment Project TRP \# 1304, National Science Foundation NSF-DUE-9453883, EduTech Institute, state of Georgia, and Boeing Computer Services. In addition, the authors would like to thank the members of the Boeing Defense and Space Group, Boeing Commercial Airplane Group Customer Service and Boeing Measurement systems Research and Development.

\section{References}

1. Cook, J. Marvin. "Using Mapping for Course Development," Info-Line, April 1991, Issue 104, American Society for Training and Development: Alexandria, VA.

2. Haines, Lewis A. "Task Analysis as a Basis for the Development of a Training System," Proc. IEEE Conference on Aerospace and Electronics 1993, pp. 691-695.

3. Hall, Brandon. "Return-On-Investment and Multimedia Training," Multimedia Training Newsletter, Macromedia, Inc., 1995. 